\title{
Role of guaifenesin in the management of chronic bronchitis and upper respiratory tract infections
}

\author{
Helmut H. Albrecht ${ }^{1}$, Peter V. Dicpinigaitis ${ }^{2}$ and Eric P. Guenin ${ }^{3 *}$
}

\begin{abstract}
Guaifenesin, a mucoactive drug, acts by loosening mucus in the airways and making coughs more productive. It is used for relief of wet cough and chest congestion due to the common cold, and remains the only legally marketed expectorant in the US (per OTC Monograph). An ingredient in numerous over-the-counter (OTC) cough/cold medications, guaifenesin has a secondary indication for use in stable chronic bronchitis (professional indication). Clinical pharmacology and patient studies support the clinical utility of guaifenesin in respiratory conditions where mucus hypersecretion is prevalent: acute upper respiratory tract infections (URTIs), stable chronic bronchitis, and possibly rhinosinusitis. Guaifenesin has a well-established and favorable safety and tolerability profile in adult and pediatric populations. Its dosing range (200-400 mg 4-hourly, up to 6x daily) allows flexible dose titration to allow an increase of plasma concentrations. Multiple daily doses are needed to maintain 24-h therapeutic effect with immediaterelease formulations. Extended-release guaifenesin tablet formulations are available, providing convenience with 12-hourly dosing and portability compared to liquids. Guaifenesin is considered as a safe and effective expectorant for the treatment of mucus-related symptoms in acute URTIs and stable chronic bronchitis. Its clinical efficacy has been demonstrated most widely in chronic respiratory conditions, where excess mucus production and cough are more stable symptoms. Progress is being made to establish clinical models and measures that are more appropriate for studying symptomatic relief with guaifenesin in acute respiratory infections. This will help generate the up-to-date and high-quality data needed to optimize guaifenesin's effectiveness in established uses, and in new respiratory indications associated with mucus hypersecretion.
\end{abstract}

Keywords: Guaifenesin, Mucus, Cough, Expectorant, Chronic bronchitis, Respiratory tract infections, Mucociliary clearance; over-the-counter (OTC), Extended-release (ER) formulation, Mucoactive agents

\section{Background}

Respiratory conditions have been known throughout most of recorded medical history, and today mortality and morbidity associated with respiratory conditions represent a substantial global health burden. Statistics show over a hundred million people living with chronic respiratory conditions worldwide [1], while acute respiratory infections are among the most common reasons for physician office visits [2].

Pathological hypersecretion of mucus is a common feature in many acute and chronic respiratory conditions. Expectorants are used empirically to treat cough with an

\footnotetext{
* Correspondence: eric.guenin@rb.com

${ }^{3}$ Reckitt Benckiser, LLC, 399 Interpace Parkway, Parsippany, NJ 07054, USA Full list of author information is available at the end of the article
}

underlying cause of pathological mucus, by targeting various mechanisms that promote increased mucus hydration and clearance from the respiratory tract. Guaifenesin, or glyceryl guaiacolate ether (GGE), is an oral expectorant and a common ingredient in prescription and over-thecounter (OTC) medicines for respiratory conditions. Despite its wide use for the symptomatic management of chest congestion and cough associated with acute upper respiratory tract infections (URTIs), such as the common cold, guaifenesin's precise mechanism of action has not been fully elucidated.

The use of guaifenesin as a natural remedy dates back to the 1500s, when guaiac tree extracts were used by Native Americans to treat various illnesses (Table 1). The drug was first accepted in 1952 by the US Food and Drug 
Table 1 Brief history of guaifenesin and its regulatory path in the US

\begin{tabular}{ll}
\hline Time & Key events \\
\hline Pre-1500s & Used as natural remedy by Native Americans \\
1500s & $\begin{array}{l}\text { Guaiac extract used as stimulant remedies, e.g. for } \\
\text { sore throat, syphilis } \\
\text { 1800s }\end{array}$ \\
& Guaiac extract used to treat respiratory diseases \\
& in Europe \\
& First accepted by US Food and Drug Administration \\
& (FDA) \\
& $\begin{array}{l}\text { Guaifenesin was reclassified to Category I (generally } \\
\text { recognized as safe and effective) and was included } \\
\text { in the Final Monograph (Cold, Cough, Allergy, } \\
\text { Bronchodilator, and Antiasthmatic Drug Products for } \\
\text { Over-the-Counter Human Use, 21 CFR 341) as an } \\
\text { expectorant for the symptomatic treatment of colds } \\
\text { and stable chronic bronchitis. } \\
\text { 12-h extended-release (ER) guaifenesin bi-layer tablets } \\
\text { were approved by the FDA. From 2007, the FDA } \\
\text { removed all marketed, but unapproved, timed-release } \\
\text { guaifenesin products from the market. }\end{array}$ \\
\hline
\end{tabular}

Administration (FDA); in 1989, it was included in the Final Monograph for 'Cold, Cough, Allergy, Bronchodilator, and Anti-asthmatic Drug Products for Over-the-Counter Human Use' [3], 21 CFR 341. Inclusion in the Monograph established guaifenesin as a safe and effective expectorant for the symptomatic treatment of acute URTIs and also allowed use of the drug in stable chronic bronchitis. Today, guaifenesin is still the only OTC expectorant legally marketed in the US.

The purpose of this article is to review scientific evidence for the use of guaifenesin in different respiratory conditions and to summarize the key clinical studies. As a single-ingredient product, guaifenesin has an acceptable safety profile in both adult and pediatric populations. We describe recent advances in the understanding of guaifenesin's mechanism of action and briefly discuss the rationale for its use in the context of its pharmacology, pharmacodymanics, and clinical efficacy profile.

\section{Mucus in airway function and disease}

The respiratory tract is covered with a layer of mucus, which maintains airway humidification and acts as a protective barrier to inhaled particles and microorganisms. Mucus entraps inhaled particles and is then transported out of the lungs by the sweeping movements of epithelial cilia-a process termed mucociliary clearance (MCC) [4]-before being swallowed or expectorated. A dynamic balance of production, secretion, and clearance of mucus is needed to maintain airway function and health.

Respiratory conditions can dramatically alter airway mucus composition and properties. Upregulation of mucins, high molecular-weight extracellular mucopolysaccharides that are critical components of mucus, increases mucus viscosity; this can worsen congestion [5]. Pathological overproduction and hypersecretion of mucus feature prominently in chronic respiratory conditions such as chronic bronchitis, chronic obstructive pulmonary disease (COPD) and asthma [4, 6]. In fact, mucus hypersecretion has been described as a hallmark of the chronic bronchitis "phenotype" [7]. Since excessive respiratory mucus dramatically hinders MCC and serves as a trigger for cough [4], normalization of pathological mucus is a central goal of many therapeutic interventions in respiratory disease.

\section{Guaifenesin: multiple effects on pathological mucus}

Therapy with mucoactive drugs is an important factor in the treatment of respiratory conditions in which mucus hypersecretion is prevalent. A large number of drugs acting directly or indirectly on mucus have been well studied and reviewed [5, 8-12].

There are four main classes of mucoactive drugs with different mechanisms of action (Table 2). Out of these, only mucolytic and expectorant drugs act directly on mucus properties or its secretion. Earlier studies showed that guaifenesin has multiple effects on mucus, such as increasing the volume of bronchial secretions and decreasing mucus viscosity. This modulation of airway secretions enhances their clearance by promoting more effective expectoration. Guaifenesin may also have direct effects on respiratory tract epithelial cells, including suppressed mucin production, reduced mucus viscoelasticity, and improved MCC [13]. One study indicated that guaifenesin does not act directly on mucus viscosity [14]. The effects of guaifenesin are not limited to affecting mucus consistency (e.g., increasing mucus hydration or altering viscoelasticity); it appears that the drug directly or indirectly targets multiple processes, including the inhibition of cough reflex sensitivity $[15,16]$.

\section{Pharmacology \\ Pharmacokinetics}

Guaifenesin [3-(2- methoxyphenoxy)-1,2-propanediol] has been well characterized chemically [17]. Animal studies showed that guaifenesin is generally well absorbed and has an established pharmacokinetic profile. In rats, when administered by various routes including intravenous (IV) bolus, oral gavage $(50 \mathrm{mg} / \mathrm{kg}, 25 \mathrm{mg} / \mathrm{mL})$, and gastric, jejunal or cecal infusions $(50 \mathrm{mg} / \mathrm{kg}, 50 \mathrm{mg} / \mathrm{mL})$, guaifenesin achieved a maximum plasma concentration $\left(\mathrm{C}_{\max }\right)$ of 15 $33 \mu \mathrm{g} / \mathrm{mL}$ [18]. The time to reach $C_{\max }\left(T_{\max }\right)$ in rats was faster when given as an oral bolus (27 min) than with gastric, jejunal or cecal infusions (120 min) [18]. In rats, the bioavailability of guaifenesin for all gastrointestinal (GI) routes was $\sim 70 \%$, and the terminal half-life of IV administration ( 45 min) was identical to that associated with various GI routes of administration (45$54 \mathrm{~min}$ ) [18]. 
Table 2 Main classes of mucoactive drugs

\begin{tabular}{ll}
\hline Mucoactive drug classes & Proposed mechanism of action (example) \\
\hline Expectorants & Increase mucus secretion volume and/or hydration for more productive cough (e.g. guaifenesin) \\
Mucolytics & Reduce mucus viscosity by breaking down tertiary structures within mucus (e.g. N-acetylcysteine) \\
Mucokinetics & Increase mucus transportability by mucociliary transport and cough mechanisms (e.g. ambroxol) \\
Mucoregulators & Affect the regulation of mucus synthesis and reduce mucus hypersecretion (e.g. anticholinergic agents) \\
\hline
\end{tabular}

Guaifenesin is well absorbed from the human GI tract. Following a single oral dose of guaifenesin in pediatric subjects, $\mathrm{C}_{\max }$ was reached in approximately $0.5 \mathrm{~h}$ and the plasma elimination half-life was approximately $1 \mathrm{~h}$ [19]. In adult subjects, $C_{\max }$ was achieved in $1.69 \mathrm{~h}$ following a single oral dose of IR guaifenesin; the terminal

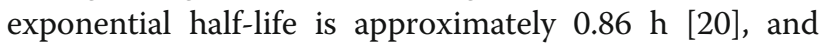
the compound is no longer detectable in the blood at $8 \mathrm{~h}$ post dose.

Once absorbed, guaifenesin is efficiently metabolized and subsequently excreted in the urine. Guaifenesin is not known to interfere with the cytochrome P450 (CYP) system, nor is it an inhibitor or inducer of this system. Guaifenesin appears to undergo both oxidation and demethylation. The drug is rapidly metabolized in the liver via oxidation to $\beta$-(2-methoxyphenoxy)-lactic acid [21]. The demethylation of GGE (hydroxyguaifenesin) is performed by O-demethylase, localized in liver microsomes; approximately $40 \%$ of a dose is excreted as this metabolite in the urine within $3 \mathrm{~h}$. O-demethylase seems to be the main enzyme for the metabolism of GGE [22, 23]. Following oral dosing ( $400 \mathrm{mg}$ ), more than $60 \%$ of a dose is hydrolyzed within $7 \mathrm{~h}$, with no parent drug detectable in the urine [24]. The major metabolites of guaifenesin (both inactive) are beta-2-methoxyphenoxy-lactic acid [21, 25] and hydroxy-guaifenesin [22].

\section{In vitro and animal studies investigating the mechanism of action}

To date, several mechanisms of action have been described for guaifenesin. It has been postulated that guaifenesin exerts its expectorant activity via a neurogenic mechanism: a stimulation of vagal afferent nerves in the gastric mucosa activates the gastro-pulmonary reflex, and increases the hydration of airway mucus $[26,27]$. In support of this hypothesis, a study in rats demonstrated that oral but not intravenous guaifenesin administration increased respiratory secretions [18].

The viscoelastic behavior of bronchial mucus has important consequences for mucociliary clearance. This mucus is an adhesive, viscoelastic gel, the biophysical properties of which are largely determined by entanglements of long polymeric gel-forming mucins: MUC5AC (expressed in goblet cells) and MUC5B (originating from submucosal glands) [11]. Inflammatory airway diseases and infections cause mucus (including mucin glycoproteins) overproduction and hypersecretion from metaplastic and hyperplastic goblet cells which contributes to mucus obstruction of airways [6]. Medications that decrease viscoelasticity, such as certain mucolytics, may benefit ciliary clearance.

Recent in vitro studies using differentiated human airway epithelial cells, grown at an air-liquid interface to mimic physiological conditions in the respiratory tract, revealed direct effects of guaifenesin on the airway epithelium $[13,28]$. At clinically relevant doses, guaifenesin was found to significantly decrease mucin (MUC5AC) production, mucus viscosity and elasticity, and to enhance MCC [13]. These results were replicated in another study on airway epithelial cells pre-treated with an inflammatory mediator, IL-13, to increase secretions prior to treatment with guaifenesin, $\mathrm{N}$-acetylcysteine, or ambroxol [28]. Guaifenesin was more effective than N-acetylcysteine or ambroxol at increasing MCC rates, inhibiting mucin secretion, and improving mucus rheology. Figure 1 shows some of these putative mechanisms of action (Fig. 1a,-d). Additional in vivo pharmacology and clinical studies will be needed to further elucidate these findings and determine how these mechanisms can be most effectively recruited to produce clinically relevant effects in the target populations.

\section{Human studies investigating the mechanism of action of guaifenesin}

Studies in patients with chronic bronchitis demonstrated that guaifenesin increases MCC [29] and reduces sputum viscosity [30]. Bennett and coworkers compared the effects of guaifenesin and placebo on in vivo MCC by measuring the rate of removal of inhaled radioactive tracer particles from the lungs of healthy, non-smoking adults. Guaifenesin enhanced small airway clearance with a strong trend toward statistical significance $(p=0.07)$ [31]. In a similar study with a crossover design to assess the effects of guaifenesin on MCC and cough clearance (MCC/CC) in adults with acute RTIs, it was reported that the effect of a single dose of guaifenesin on MCC/CC could not be differentiated from that of placebo in that study population [32].

A study in healthy volunteers with a history of sinus disease did not detect significant differences between guaifenesin and placebo treatment in terms of their effects on in vivo nasal MCC [33]. Saccharin particle transit time (STT) was similar with guaifenesin and placebo, and it was suggested that additional factors could have an impact on MCC and/or ciliary motility. 

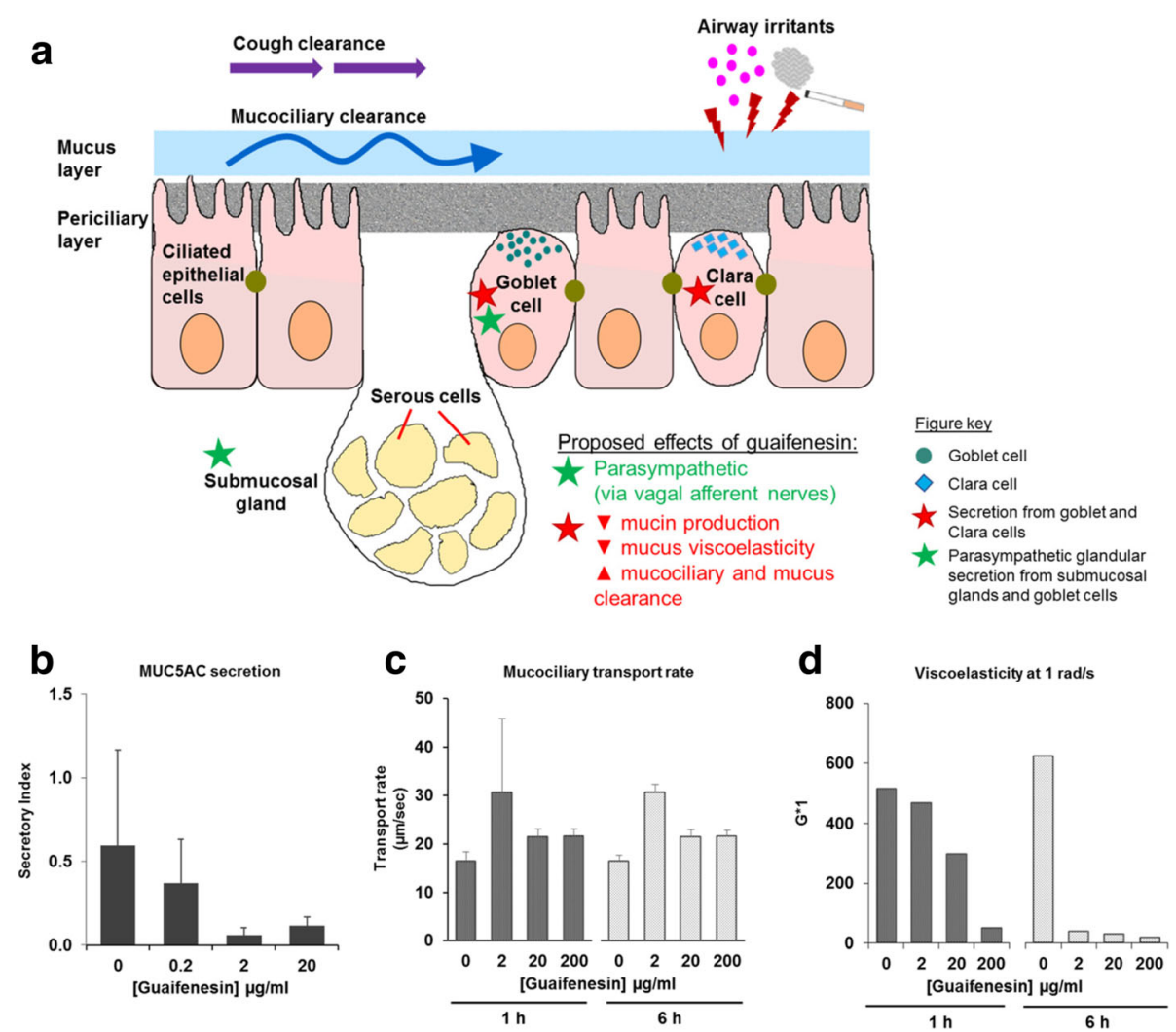

Fig. 1 Putative effects of guaifenesin on mucus in chronic or acute hypersecretory respiratory conditions. a The airway is composed of a mucus gel layer covering the epithelium, which includes ciliated cells, Clara cells, goblet cells and submucosal glands. The mucociliary complex can be subdivided into two layers - an upper mucus gel layer containing MUC5AC and MUC5B mucins, and a lower layer of periciliary fluid containing cell surface-tethered mucins. Mucociliary clearance (MCC) is effected by the rhythmic sweeping motion of cilia. Prolonged exposure to irritants such as cigarette smoke or allergens can lead to overproduction and hypersecretion of mucus. Guaifenesin has been postulated to promote mucociliary clearance via a number of mechanisms. (1) Indirect activation/stimulation of gastrointestinal vagal afferent nerves triggers reflex parasympathetic glandular secretion from submucosal glands and goblet cells (green stars), increasing hydration of mucus layer for more effective mucociliary clearance. Guaifenesin also affects secretion from goblet and Clara cells (red stars), resulting in (2) decreased mucin production and secretion (green circles, goblet cells; blue squares, Clara cells), and (3) reduced viscoelasticity of mucus, which increases the ability of ciliary movement to remove mucus. Together these changes serve to enhance MCC and mucus clearance. $\mathbf{b}$ - $\mathbf{d}$ Guaifenesin has direct effects on MCC-related processes in airway epithelial cells. In cultured human differentiated tracheobronchial epithelial cells, 24-h treatment with guaifenesin (2 or $20 \mathrm{\mu g} / \mathrm{mL}$ ) significantly suppressed mucin production and mucin secretion (b), while 6-h treatment with guaifenesin $(2-200 \mu \mathrm{g} / \mathrm{mL})$ significantly enhanced mucociliary transport rates (c). At $1 \mathrm{~h}$ and $6 \mathrm{~h}$ after guaifenesin treatment $(0-200 \mathrm{\mu g} / \mathrm{mL})$, significant dose-dependent decreases were observed in mucus viscosity and elasticity at typical ciliary beat frequency $(1 \mathrm{rad} / \mathrm{s})(\mathbf{d})$, as measured by $\mathrm{G}^{*} 1$ (vector sum of viscosity and elasticity at $\left.1 \mathrm{rad} / \mathrm{s}\right)$. Panels b-d adapted from Seagrave et al., 2011 [13]

Guaifenesin has been shown to make coughs more productive [34], and additionally has been found to inhibit cough reflex sensitivity in subjects with acute URTIs $[15,16]$. Two double-blind, randomized and placebocontrolled studies investigated the effect of a single dose of guaifenesin (400 $\mathrm{mg}$ and $600 \mathrm{mg}$, respectively) on participants' response to a nebulized capsaicin cough challenge. Guaifenesin significantly reduced cough reflex sensitivity in patients with viral URTIs $[15,16]$, but not in healthy volunteers. The authors suggested that this effect was limited to patients with URTIs due to their transiently increased cough receptor sensitivity.

Details of clinical studies mentioned in this section are in Table 3.

\section{Clinical efficacy studies in respiratory diseases}

\section{Clinical uses of guaifenesin}

Despite the large number of clinical studies on different clinical aspects of guaifenesin therapy, its expectorant indication is currently the only one that the FDA considers to be supported by sufficient medical evidence. The "Cough-Cold" Final OTC Monograph covers the use of guaifenesin in adults and children 2 years and older, and is based on a subset of clinical studies in chronic respiratory diseases that were available when the monograph was developed. The Monograph indication for guaifenesin is limited to symptomatic treatment of acute URTIs and stable chronic bronchitis [3]. The FDA approved labels for guaifenesin include an OTC label for its 


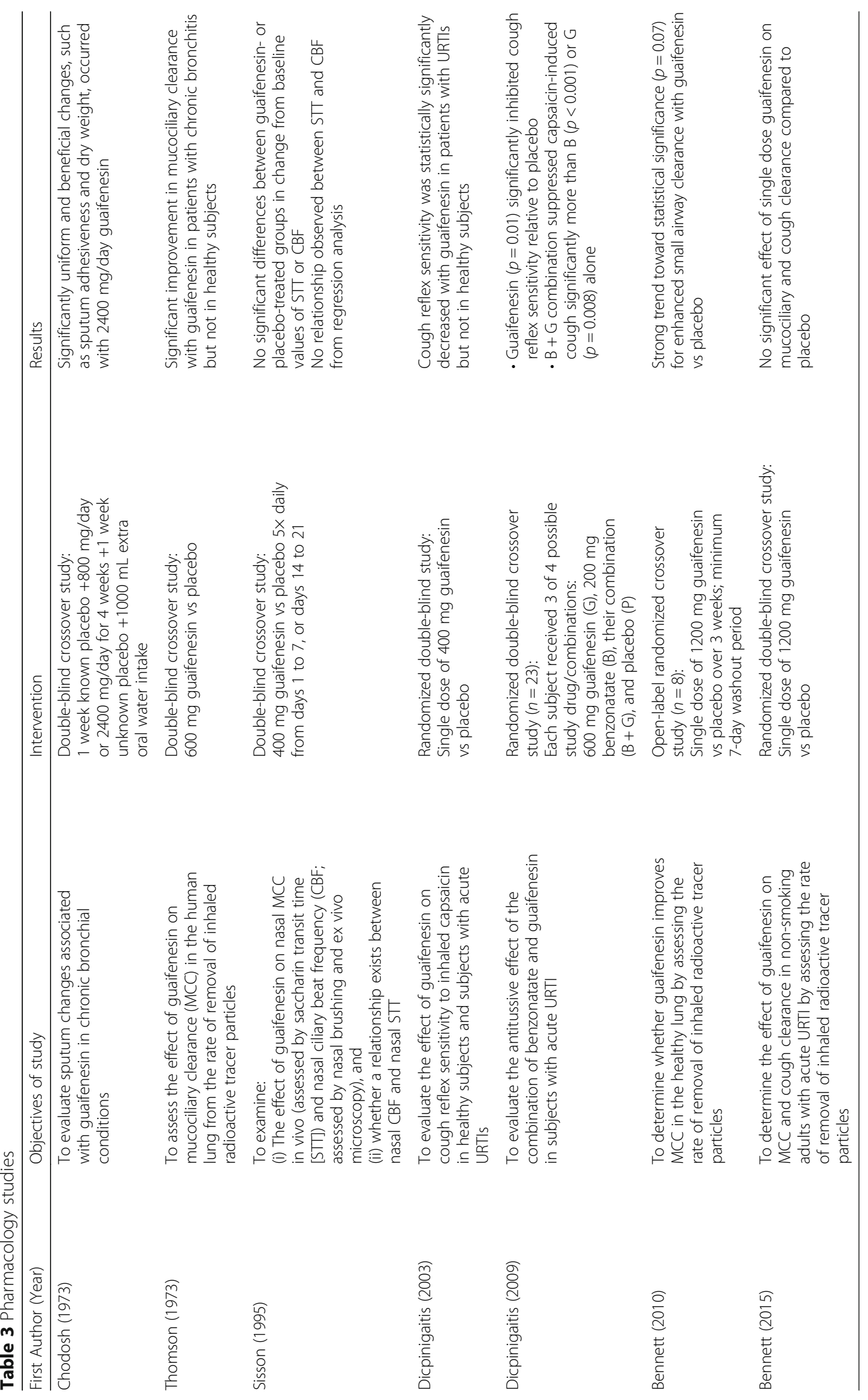


use in the treatment of chest congestion associated with an URTI but also a professional label for chest congestion associated with stable chronic bronchitis for its detailing to healthcare professionals. This professional label indication mirrors the outcome of clinical studies conducted on chronic bronchitis patients. The exact wording of the indications is listed below:

- Guaifenesin "helps loosen phlegm (mucus) and thin bronchial secretions -

$\circ$ to rid the bronchial passageways of bothersome mucus and make coughs more productive" (OTC uses)

○ in patients with stable chronic bronchitis" (professional indication).
A review of the literature supporting the clinical utility of guaifenesin shows effects across three categories of respiratory conditions: chronic bronchitis and chronic respiratory conditions (Table 4), URTIs (Table 5), and rhinosinusitis (Table 6). Almost all studies discussed here were conducted in adults, with the exception of one published study in children on the use of guaifenesin for relieving cough symptoms [35].

It should be noted that stable chronic respiratory conditions, such as chronic bronchitis, have proved more reliable as clinical models for studying the effects of expectorants and other mucoactive drugs. Mucus production and associated cough symptoms tend to be more stable in chronic respiratory conditions, allowing the effects of guaifenesin to be observed more consistently.

Table 4 Clinical efficacy studies: Chronic bronchitis and chronic respiratory conditions

\begin{tabular}{|c|c|c|c|}
\hline Author (Year) & Objectives of study & Intervention & Results \\
\hline Hayes (1956) & $\begin{array}{l}\text { To determine the effectiveness of Robitussin }{ }^{\circledast} \\
\text { as an expectorant in productive cough due } \\
\text { to chronic pulmonary disease }\end{array}$ & $\begin{array}{l}1-2 \mathrm{~g} \text { Robitussin }{ }^{\circledast} \text { (containing } \\
100 \mathrm{mg} \text { guaifenesin and } 1 \mathrm{mg} \\
\text { desoxyephedrine } \mathrm{HCl} \text { per } 5 \mathrm{~mL} \text { ) } \\
\text { vs placebo every } 2-3 \mathrm{~h} \text {, as required }\end{array}$ & $\begin{array}{l}\text { Statistically significant changes compared } \\
\text { to placebo: } \\
\text { - Reduction in chronic productive cough } \\
\text { - Decreased frequency of cough and } \\
\text { sputum viscosity }\end{array}$ \\
\hline Chodosh (1964) & $\begin{array}{l}\text { To investigate the efficacy and mechanism } \\
\text { of action of guaifenesin in bronchopulmonary } \\
\text { diseases }\end{array}$ & $\begin{array}{l}\text { Double-blind study: } \\
100 \text { mg guaifenesin tablet } 4 \times \\
\text { daily vs placebo for } 14 \text { days } \\
\text { (after placebo run-in) }\end{array}$ & $\begin{array}{l}\text { Statistically significant changes compared } \\
\text { to placebo: } \\
\text { - Increase in ease of expectoration } \\
\text { - Decrease in the measured sputum surface } \\
\text { tension }\end{array}$ \\
\hline
\end{tabular}

Hirsch (1973) To investigate the expectorant effect of guaifenesin in patients with chronic bronchitis

Wojcicki (1975) To investigate the effect of guaifenesin on: (i) Severity and frequency of cough, and (ii) Tenaciousness of sputum

Finiguerra (1982) (unpublished; data on file)

Parvez (1996)
To determine the efficacy of guaifenesin for: (i) Modifying the volume and viscosity of tracheobronchial secretions, and in (ii) Providing symptomatic relief of difficult expectoration and cough in chronic bronchitis

To determine the usefulness of a multidimensional cough quantitation system for evaluating guaifenesin's effects on cough and sputum
Single-blind crossover study: $800 \mathrm{mg}$ or $1600 \mathrm{mg}$ guaifenesin vs placebo alternating for 5 weeks Double-blind crossover study: $1600 \mathrm{mg}$ guaifenesin vs placebo daily for 5 days

Double-blind crossover study: $120 \mathrm{mg}$ guaifenesin vs $17 \mathrm{mg}$ narcotine $\mathrm{HCl}$, vs combination (120 mg guaifenesin $+17 \mathrm{mg}$ narcotine $\mathrm{HCl}$ ), vs placebo, $3 \times$ daily for 7 days (per treatment)

Randomized double-blind parallelgroup study:

190 mg guaifenesin vs placebo,

$3 \times$ daily for 15 days

Randomized double-blind parallelgroup study:

$300 \mathrm{mg}$ guaifenesin vs placebo,

$4 \times$ daily for 14 days
No significant difference between guaifenesin and placebo in reducing sputum consistency, increasing sputum volume, improving ventilatory function or ease of expectoration

Guaifenesin + narcotine $\mathrm{HCl}$ combination associated with statistically significant decreases in:

- Cough severity

- Cough frequency

Statistically significant changes:

- Decrease in sputum volume and viscosity

- Decrease in cough severity

- Improvement in ease of expectoration

Differences between guaifenesin and placebo groups:

- Guaifenesin significantly increased sputum volume; $37 \%$ difference on day $14(p<0.05)$

- Significant reduction in fucose, a biomarker for sputum glycoprotein, in the guaifenesin group at day 14 $(p<0.01)$

- Subjective measure of average intensity/cough at day $4(p<0.05)$

- Trend for greater improvement in ease of expectoration at days 10 and 14 in the guaifenesin group but did not reach significance in the subgroup with productive cough $(p<0.01)$ 
Table 5 Clinical efficacy studies: Upper respiratory tract infections

\begin{tabular}{|c|c|c|c|}
\hline First Author (Year) & Objectives of study & Intervention & Results \\
\hline Robinson (1977) & $\begin{array}{l}\text { To confirm that guaifenesin was } \\
\text { superior to placebo in facilitating } \\
\text { expectoration of sputum and } \\
\text { ameliorating dry cough in patients } \\
\text { with an acute upper respiratory } \\
\text { infection }\end{array}$ & $\begin{array}{l}\text { Randomized double-blind } \\
\text { parallel-group study: } \\
200 \text { mg guaifenesin in } \\
10-\mathrm{mL} \text { doses vs placebo, } \\
4 \times \text { daily for } 3 \text { days }\end{array}$ & $\begin{array}{l}\text { Subjective measures compared to placebo: } \\
\text { - Cough frequency reduced at } 48 \mathrm{~h}, 72 \mathrm{~h} \text { (all: } p<0.01 \text { ) } \\
\text { - Cough intensity reduced at } 48 \mathrm{~h}, 72 \mathrm{~h} \text { (all: } p<0.01 \text { ) } \\
\text { - Chest discomfort reduced at } 24 \mathrm{~h}, 48 \mathrm{~h}, 72 \mathrm{~h} \text { (all: } p<0.01 \text { ) } \\
\text { - Sputum volume increased (only in patients with } \\
\text { productive cough) at } 48 \mathrm{~h}(p<0.01 \text { ) } \\
\text { - Ease of raising sputum increased at } 24 \mathrm{~h}, 48 \mathrm{~h}, 72 \mathrm{~h} \text { (all: } \\
\quad p<0.01 \text { ) }\end{array}$ \\
\hline Kuhn (1982) & $\begin{array}{l}\text { To evaluate the efficacy of guaifenesin } \\
\text { in reducing cough frequency in adults } \\
\text { with acute respiratory disease }\end{array}$ & $\begin{array}{l}\text { Double-blind study: } \\
2400 \text { mg guaifenesin } \\
\text { vs placebo syrup vehicle } \\
\text { in } 30 \text {-mL doses every } \\
6 \mathrm{~h} \text { for } 30 \mathrm{~h}\end{array}$ & $\begin{array}{l}\text { - Objective cough counts: No significant differences } \\
\text { between guaifenesin and placebo } \\
\text { - Significantly greater decrease in sputum viscosity } \\
\text { compared to baseline in patients with productive cough } \\
(p=0.001) \\
\text { - Greater decrease in sputum quantity }(p=0.07)\end{array}$ \\
\hline Albrecht (2012) & $\begin{array}{l}\text { Pilot study to determine the efficacy } \\
\text { of extended-release (ER) guaifenesin } \\
\text { with placebo for treatment of URTI, } \\
\text { using objective and subjective efficacy } \\
\text { assessments }\end{array}$ & $\begin{array}{l}\text { Randomized double- } \\
\text { blind study: } \\
1200 \text { mg ER guaifenesin } \\
\text { vs placebo } 2 \times \text { daily for } \\
7 \text { days }\end{array}$ & $\begin{array}{l}\text { Subjective measures of efficacy (patient-reported } \\
\text { outcomes; PROs) showed the most prominent differences } \\
\text { between treatment groups at Day 4, in favor of guaifenesin. } \\
\text { Based on post-hoc analyses focusing on subsets of these } \\
\text { PROs, an 8-question PRO tool (SUM8) was validated. }\end{array}$ \\
\hline
\end{tabular}

\section{Chronic bronchitis and chronic respiratory conditions} The inclusion of guaifenesin in the 1989 Final OTC Monograph was essentially supported by four clinical studies in patients with chronic bronchitis [36-39]. All of these definitive studies demonstrated statistically superior efficacy of guaifenesin versus controls in improving ease of expectoration, decrease in sputum surface tension and viscosity, or reduction in the frequency and severity of cough (Table 4).

An early study in chronic bronchitis patients reported that guaifenesin's effects on sputum consistency and volume were comparable to that of placebo [40]. Other studies, however, support the drug's effects on sputum. Although results for cough assessments in patients with chronic bronchopulmonary disease were mixed, guaifenesintreated patients reported increased sputum volume compared with placebo, as well as greater ease of expectoration [41]. These findings are consistent with an earlier study on objective sputum changes in patients with chronic bronchitis; guaifenesin was found to significantly decrease sputum adhesiveness and quantity (dry weight), and was also reported to improve expectoration [30].

\section{Acute upper respiratory tract infections (URTIs)}

The efficacy of guaifenesin as an expectorant has also been examined in the context of acute URTIs (Table 5). Robinson and coworkers showed that guaifenesin improved acute URTI symptoms based on patient-assessed subjective measures (cough frequency and intensity) and physicians' evaluation of global effectiveness [42]. In adults with acute URTIs, guaifenesin significantly reduced sputum thickness and quantity compared to placebo [41].

A large placebo-controlled pilot study explored a range of objective and subjective outcome measures in patients with acute URTIs. The most promising measures included a daily diary for patient-reported outcome (PRO) parameters. These described symptoms such as severity of chest congestion, mucus thickness and cough. Some of these 11 exploratory parameters showed strong trends or statistically significant differences between guaifenesin and placebo. A PRO validation process served to qualify more focused subsets of 4 and 8 questions. Based on post-hoc analyses ( $p=$ 0.038), an 8-question PRO tool (SUM8) was validated and proposed for use in future respiratory studies [43]. To explore effects on sputum as objective endpoints, laboratory analyses were performed on patient mucus samples from

Table 6 Clinical efficacy studies: Rhinosinusitis

\begin{tabular}{llll}
\hline First Author (Year) & Objectives of study & Intervention & Results \\
\hline Wawrose (1992) & $\begin{array}{l}\text { To evaluate the role of guaifenesin in } \\
\text { decreasing symptoms of postnasal } \\
\text { drainage and nasal congestion in HIV+ } \\
\text { patients with chronic rhinosinusitis }\end{array}$ & $\begin{array}{l}\text { Double-blind parallel-group study: } \\
1200 \mathrm{mg} \text { guaifenesin vs placebo }\end{array}$ & $\begin{array}{l}\text { Significantly less nasal congestion and } \\
\text { thinner postnasal drainage reported after }\end{array}$ \\
& $\begin{array}{l}\text { To evaluate the effect of guaifenesin } 3 \text { weeks } \\
\text { Rosen (2005) }\end{array}$ & $\begin{array}{l}\text { Randomized double-blind parallel- } \\
\text { on mucociliary clearance time (MCT) }\end{array}$ & $\begin{array}{l}\text { Significant improvement in sinonasal } \\
\text { vs placebo }(p<0.05)\end{array}$ \\
& and sinonasal symptoms in HIV+ patients & 1200 mg guaifenesin vs placebo & $\begin{array}{l}\text { symptom survey (SNOT-16) score in HIV+ } \\
\text { patients treated with guaifenesin vs placebo } \\
(p<0.05)\end{array}$ \\
& $2 \times$ daily for 3 weeks & \\
\hline
\end{tabular}


the pilot study. The laboratory analyses could not demonstrate differences in mucus properties with guaifenesin compared to placebo; however, it should be noted that methodological issues with mucus sample collection and shipping were present, raising some questions about the interpretation of the laboratory results [44].

\section{Rhinosinusitis}

Guaifenesin was reported to be effective for improving symptomatic rhinitis and sinusitis by decreasing nasal congestion and postnasal discharge in immunocompromised HIV positive patients [45, 46]. Despite some conflicting data available, some patients with rhinitis benefit from using guaifenesin [12]. Further research is needed to clarify guaifenesin's effects on congestion and mucus clearance from the nasal passages and sinuses in the general patient population.

\section{Clinical safety}

As a single agent, guaifenesin has a well-established and favorable safety and tolerability profile. Its safety record is supported by data from published clinical studies and a history of post-marketing surveillance safety reports covering more than 50 years in the US and around the world. Common side effects reported for the drug include dizziness, headache, and gastrointestinal disturbances at high doses [17].

Retrospective and ongoing prospective pediatric safety data analyses confirm guaifenesin's favorable safety profile as an OTC drug in children [47, 48]. In a continuous safety surveillance analysis of 8 common cough and cold drugs conducted from 2008 through 2014, guaifenesin showed the lowest number of "at least potentially related" non-fatal adverse event (AE) cases (1\%) out of a total of 5610 index drug reports [48]. Guaifenesin had the lowest frequency of mentions for non-fatal AEs by system organ class (SOC) at estimated supra-therapeutic and even at estimated unknown dosing; and the second lowest frequency of mentions for non-fatal AEs by SOC at estimated therapeutic dosing. More importantly, guaifenesin was not mentioned in any "potentially related" fatal cases during the 1991-2008 surveillance period, or during the 2008-2014 detection period.

The few published reports of serious adverse events related to the use of guaifenesin have mostly been in the context of overdose and use as part of multiple-drug combinations for various cough and cold indications. Published reports include renal stone formation with chronic guaifenesin overdose [49], and acute fatal intoxication by a combination of guaifenesin, diphenhydramine, and chlorpheniramine, although the relative contribution of guaifenesin to the fatality could not be determined [50].

Pregnancy category $\mathrm{C}$ status for GGE was determined by the FDA based on the absence of definitive studies assessing potential risks to the fetus [3,51]. Results of a recently published study in female, pregnant rats, after testing very high doses of guaifenesin, suggest that the risk of fetal abnormalities cannot be ruled out [52]. The medical literature and safety databases do not show meaningful signals suggesting a significant risk of fetal development issues after pregnant women used guaifenesin. Thus, caution regarding the use of GGE in pregnant women is warranted [51]. The current labeling ("if pregnant, ask a health professional before use") is in line with the FDA OTC Monograph and seems to be an appropriate warning telling women to avoid taking the drug during pregnancy.

\section{Guaifenesin drug products and dosing}

Immediate-release (IR) and extended-release (ER) guaifenesin are available in single-agent formulations (Table 7). There are also many popular guaifenesin-containing combination OTC and prescription products available on the market, but these are outside the scope of this article. The dual dosing range of guaifenesin in the US allows patients the flexibility to titrate doses to achieve optimal efficacy.

Table 7 Examples of currently available over-the-counter guaifenesin formulations and recommended doses in the US and Canada

\begin{tabular}{|c|c|c|c|}
\hline Formulation & Population & Recommended doses & Available dosage form - Product example(s) \\
\hline Immediate-release & Children -2 to $<6$ years & $\begin{array}{l}\text { US: } 50-100 \text { mg up to 4-hourly; max } \\
600 \text { mg/day } \\
\text { Canada: Not recommended }\end{array}$ & $\begin{array}{l}\text { Syrup - CVS Health }{ }^{\circledast} \text { Children's Mucus } \\
\text { Relief Chest Congestion } \\
\text { Soft chews - Kids-EEZE } \\
\text { Chest Relief }\end{array}$ \\
\hline Immediate-release & Children -6 to $<12$ years & $\begin{array}{l}\text { US: } 100-200 \text { mg up to 4-hourly; max } \\
1200 \text { mg/day } \\
\text { Canada: Not recommended }\end{array}$ & $\begin{array}{l}\text { Syrup - CVS Health }{ }^{\oplus} \text { Children's Mucus } \\
\text { Relief Chest Congestion } \\
\text { Soft chews - Kids-EEZE } \\
\text { Chest Relief }\end{array}$ \\
\hline Immediate-release & Adults and children 12 years and older & $\begin{array}{l}\text { US: } 200-400 \text { mg up to } 4 \text {-hourly; max } \\
2400 \text { mg/day } \\
\text { Canada: } 200-400 \text { mg up to 6-hourly; } \\
\text { max } 1600 \text { mg/day }\end{array}$ & $\begin{array}{l}\text { Tablet - Bidex }{ }^{\circledast} \\
\text { Syrup - Robitussin }{ }^{\oplus} \text { Mucus \& Chest } \\
\text { Congestion; Scot-Tussin Expectorant } \\
\text { Soft chews - Kids-EEZE }{ }^{\oplus} \text { Chest Relief }\end{array}$ \\
\hline Extended-release & Adults and children 12 years and older & $\begin{array}{l}\text { US: } 600-1200 \text { mg up to } 12 \text {-hourly; max } \\
2400 \text { mg/day } \\
\text { Canada: } 600 \text { mg ( } 1 \text { tablet) up to } \\
\text { 12-hourly; max } 1200 \text { mg/day ( } 2 \text { tablets) }\end{array}$ & Tablet - Mucinex ${ }^{\circledast}$ \\
\hline
\end{tabular}


In the US, adults and children above 12 years old may take guaifenesin in oral doses of 200 to $400 \mathrm{mg}$ every $4 \mathrm{~h}$, up to a maximum of $2400 \mathrm{mg}$ over $24 \mathrm{~h}$ [17]. Pediatric doses cater to children aged 2-12 years, and differ according to age groups, i.e. 2-6 years and 6-12 years (Table 7). In Canada, guaifenesin is not recommended for children aged 12 years and below. Dosing regimens and daily maximum doses for adults and children above 12 years old in Canada (daily dose of $1600 \mathrm{mg}$ maximum) also differ from those in the US [53].

Because of guaifenesin short half-life, frequent dosing with IR guaifenesin is required to maintain therapeutic levels of the drug in the body (Fig. 2). Subsequently 12-h extended release form of guaifenesin were designed to provide bioequivalent pharmacokinetic characteristics to generic IR guaifenesin products [20] and are currently approved as 12-h tablet ER guaifenesin formulation in the US market. An example of such ER products is a bilayer tablet formulation containing $600 \mathrm{mg}$ of guaifenesin and comprising an IR layer that allows rapid release of guaifenesin to achieve an early $\mathrm{C}_{\max }$, and an ER layer that allows sustained release of guaifenesin to produce a steady plasma concentration over a 12-h period (Fig. 2). Following approval of this extended release form of guaifenesin (NDA-21-282) in 2002, the FDA required the removal of all marketed, but unapproved, timed-release guaifenesin products from the market by 2007 .

\section{Conclusions}

This review provides an updated and comprehensive perspective on the use of guaifenesin in treating respiratory disorders in which excessive mucus is an important clinical

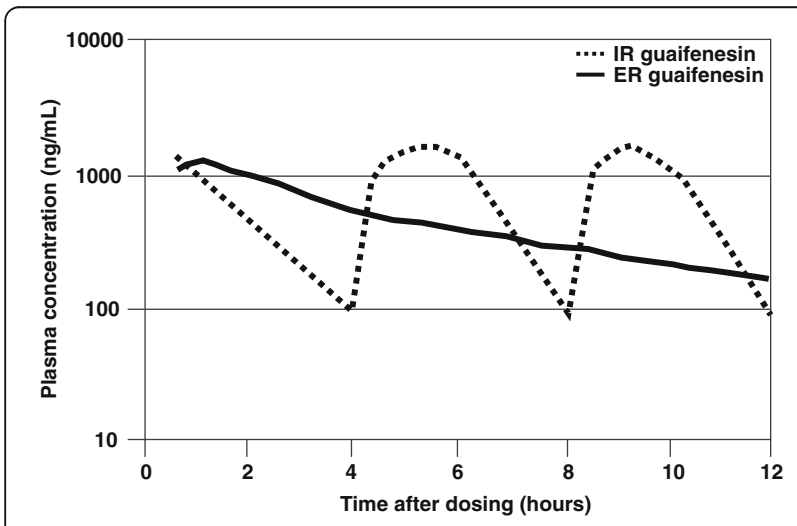

Fig. 2 Schematic pharmacokinetic profile of extended-release (ER) vs immediate-release (IR) guaifenesin formulations. Extended-release (ER) guaifenesin (blue line) attained bioequivalent plasma concentrations to those obtained with 3 immediate-release (IR) guaifenesin doses (orange line). The unique bi-layer tablet formulation comprises an IR layer that permits immediate release of guaifenesin to rapidly attain maximum plasma concentrations $\left(C_{\text {max }}\right)$, and an ER layer that permits sustained release of guaifenesin to maintain prolonged blood plasma levels of guaifenesin over $12 \mathrm{~h}$. Figure adapted from Vilson and Owen, 2013 [20] feature. Excessive mucus secretion and local accumulation in the airway occurs in both acute URTIs and chronic respiratory disorders with an underlying inflammatory etiology (such as chronic bronchitis and COPD). The expectorant properties of guaifenesin, which help to thin bronchial secretions and promote mucus clearance, were demonstrated in studies involving patients with chronic bronchitis or other chronic respiratory conditions. These studies played an important role in the FDA's decision to include guaifenesin as an expectorant in the respective Final OTC Monograph labeled for the relief of mucusrelated symptoms of acute URTIs and stable chronic bronchitis. Additional studies have been performed to clarify the mode of action and assess guaifenesin's efficacy and safety in other clinical indications [13, 28, 29, 42, 45, 46, 54].

Recent advances in the understanding of guaifenesin's mechanism of action add to the understanding of the drug's potential in the management of hypersecretory respiratory conditions. Studies in symptomatic chest congestion and acute cough, as well as in acute rhino-sinusitis indications, have yielded mixed results. This may be understandable, given the context of rapidly changing symptoms in acute URTIs, which are challenging to study under standard clinical trial conditions. Some studies showed evidence of efficacy based on improvements in subjective measures as patients assessed their cough, mucus clearance, or chest congestion symptoms. However, in many cases the methods were not validated or results were not confirmed by subsequent studies. For this reason, the effects of guaifenesin have been more consistently demonstrated in stable chronic respiratory disease models. Further research is needed to clarify the antitussive effectiveness of guaifenesin and its ability to relieve chest congestion in acute URTIs in children and adults, and the utility of the drug in improving symptoms of rhino-sinusitis.

To date, the approved indications for guaifenesin have not changed from those included in the 1989 Final Monograph. Interestingly, the secondary indication for stable chronic bronchitis remains largely underutilized or unrecognized even among US medical professionals. Further progress will require improved assessment tools and appropriately designed, modern studies, to confirm guaifenesin's utility in acute and chronic hypersecretory respiratory conditions.

A large body of AE reporting data supports the safety of guaifenesin for adult and pediatric use. Unlike certain other OTC cough and cold medications, guaifenesin has not been reported to cause many serious side effects or abuse/dependence problems, and has been proven safe in studies for use in conditions such as URTIs and stable chronic bronchitis.

Well-established as a safe expectorant drug, guaifenesin has achieved common usage for the relief of mucus- 
related symptoms of acute URTIs and for patients with mucus-related symptoms in the context of stable chronic bronchitis. Additional, up-to-date, and high-quality data are needed to explore the full potential of this compound in established uses, and in new respiratory indications associated with mucus hypersecretion.

\section{Abbreviations}

AE: Adverse event; CC: Cough clearance; COPD: Chronic obstructive pulmonary disease; CYP: Cytochrome P450; ER: Extended-release; FDA: Food and Drug Administration; GGE: Glyceryl guaiacolate ether; Gl: Gastrointestinal; HIV: Human immunodeficiency virus; IL-13: Interleukin 13; IR: Immediaterelease; IV: Intravenous; MCC: Mucociliary clearance; NDA: New drug application; OTC: Over-the-counter; PRO: Patient-reported outcome; STT: Saccharin particle transit time; URTI: Upper respiratory tract infection

\section{Acknowledgements}

The authors would like to thank the subjects, clinicians, and scientists who participated in the design, conduct, and analysis of the studies described in this review paper. The authors would also like to thank Geraldine Toh, Wei Yi Kwok and the team at Tech Observer for their medical writing support and editorial assistance; this support was funded by Reckitt Benckiser, LLC.

\section{Funding}

Medical writing and editorial support in the preparation of this review article was funded by Reckitt Benckiser, LLC. There are no other sources of funding to declare.

\section{Availability of data and materials}

Not applicable.

\section{Authors' contributions}

All authors participated in drafting the manuscript, and have read and approved the final manuscript

\section{Ethics approval and consent to participate}

Not applicable.

\section{Consent for publication}

Not applicable.

\section{Competing interests}

HHA is a paid consultant to Reckitt Benckiser, LLC, and to Alitair Pharmaceuticals, Inc. PVD is a consultant to Reckitt Benckiser, Merck, and Vernalis. EPG is an employee of Reckitt Benckiser, LLC.

\section{Publisher's Note}

Springer Nature remains neutral with regard to jurisdictional claims in published maps and institutional affiliations.

\section{Author details}

${ }^{1}$ Florida International University, Herbert Wertheim College of Medicine, 11200 SW 8th St., GL 495, Miami, FL 33199, USA. ${ }^{2}$ Albert Einstein College of Medicine and Montefiore Medical Center, 1825 Eastchester Road, Bronx, NY 10461, USA. ${ }^{3}$ Reckitt Benckiser, LLC, 399 Interpace Parkway, Parsippany, NJ 07054, USA.

Received: 3 May 2017 Accepted: 13 November 2017

Published online: 11 December 2017

\section{References}

1. Ferkol T, Schraufnagel D. The global burden of respiratory disease. Ann Am Thorac Soc. 2014;11:404-6.

2. US National Center for Health Statistics. National Ambulatory Medical Care Survey: 2013 State and National Summary Tables 2013. https://www.cdc. gov/nchs/data/ahcd/namcs_summary/2013_namcs_web_tables.pdf. Accessed 21 Mar 2017.

3. United States Department of Health and Human Services. Cold, Cough, Allergy, Bronchodilator and Antihistaminic Drug Products for Over-the-
Counter Human Use; Expectorant Drug Products for Over-the-Counter Human Use; Final Monograph. 21 CFR 341. 1989. Federal Register 54 p. 8494-8509.

4. Fahy JV, Dickey BF. Airway mucus function and dysfunction. N Engl J Med. 2010;363:2233-47

5. Rogers DF. Physiology of airway mucus secretion and pathophysiology of hypersecretion. Respir Care. 2007;52:1134-46.

6. Voynow JA, Rubin BK. Mucins, mucus, and sputum. Chest. 2009;135:505-12.

7. Button B, Anderson WH, Boucher RC. Mucus Hyperconcentration as a unifying aspect of the chronic Bronchitic phenotype. Ann Am Thorac Soc. 2016;13(Suppl 2):S156-62.

8. Balsamo R, Lanata L, Egan CG. Mucoactive drugs. Eur Respir Rev. 2010;19: 127-33.

9. Houtmeyers E, Gosselink R, Gayan-Ramirez G, Decramer M. Effects of drugs on mucus clearance. Eur Respir J. 1999:14:452-67.

10. Martin C, Frija-Masson J, Burgel PR. Targeting mucus hypersecretion: new therapeutic opportunities for COPD? Drugs. 2014;74:1073-89.

11. Rubin BK. Mucolytics, expectorants, and mucokinetic medications. Respir Care. 2007:52:859-65.

12. Storms W, Farrar JR. Guaifenesin in rhinitis. Curr Allergy Asthma Rep. 2009:9:101-6.

13. Seagrave J, Albrecht H, Park YS, Rubin B, Solomon G, Kim KC. Effect of guaifenesin on mucin production, rheology, and mucociliary transport in differentiated human airway epithelial cells. Exp Lung Res. 2011;37:606-14.

14. Rubin BK. An in vitro comparison of the mucoactive properties of guaifenesin, iodinated glycerol, surfactant, and albuterol. Chest. 1999;116:195-200.

15. Dicpinigaitis PV, Gayle YE. Effect of guaifenesin on cough reflex sensitivity. Chest. 2003;124:2178-81.

16. Dicpinigaitis PV, Gayle YE, Solomon G, Gilbert RD. Inhibition of cough-reflex sensitivity by benzonatate and guaifenesin in acute viral cough. Respir Med. 2009;103:902-6.

17. Martindale. Guaifenesin. In Martindale: The Complete Drug Reference. Edited by Sweetman S: The Pharmaceutical Press; 2016.

18. Kagan L, Lavy E, Hoffman A. Effect of mode of administration on guaifenesin pharmacokinetics and expectorant action in the rat model. Pulm Pharmacol Ther. 2009:22:260-5.

19. Thompson GA, Solomon G, Albrecht HH, Reitberg DP, Guenin E. Guaifenesin pharmacokinetics following single-dose oral Administration in Children Aged 2 to 17 years. J Clin Pharmacol. 2016;56:894-901.

20. Vilson L Jr, Owen JS. Pharmacokinetic studies in healthy subjects for the development of an extended-release tablet formulation of guaifenesin: a 505(b)(2) new drug application approval. Clin Pharmacol Drug Dev. 2013;2:25-32

21. Vandenheuvel WJ, Smith $J$, Silber RH. (2-Methoxyphenoxy)lactic acid, the major urinary metabolite of glyceryl guaiacolate in man. J Pharm Sci. 1972;61:1997-8

22. Kauert G, von Meyer L, Drasch G. Investigations of guaifenesine metabolism with gas chromatography-mass spectrometry. Arch Toxicol. 1980;45:149-59.

23. Rossberg F, Luther D. Animal experiment on the absorption, distribution and elimination of C 14 - and H 3 -labelled guaiacol-glyceryl-ether. Acta Biol Med Ger. 1971;26:331-9.

24. Naito SI, Mizutani M, Osumi S, Mikawa T, Sekishiro K, Nakao K, et al. Biopharmaceutical studies on guaiacol glyceryl ether and related compounds. V J Pharm Sci. 1972:61:1212-5.

25. Pickens $C L$, Milliron $A R$, Fussner $A L$, Dversdall $B C$, Langenstroer $P$, Ferguson $S$, et al. Abuse of guaifenesin-containing medications generates an excess of a carboxylate salt of beta-(2-methoxyphenoxy)-lactic acid, a guaifenesin metabolite, and results in urolithiasis. Urology. 1999:54:23-7.

26. Yuta A, Baraniuk JN. Therapeutic approaches to mucus hypersecretion. Curr Allergy Asthma Rep. 2005;5:243-51.

27. Ziment I. Theophylline and mucociliary clearance. Chest. 1987;92:38S-43S.

28. Seagrave J, Albrecht HH, Hill DB, Rogers DF, Solomon G. Effects of guaifenesin, $\mathrm{N}$-acetylcysteine, and ambroxol on MUC5AC and mucociliary transport in primary differentiated human tracheal-bronchial cells. Respir Res. 2012;13:98.

29. Thomson ML, Pavia D, McNicol MW. A preliminary study of the effect of guaiphenesin on mucociliary clearance from the human lung. Thorax. 1973; 28:742-7.

30. Chodosh S. Objective sputum changes associated with glyceryl guaiacolate in chronic bronchial diseases. Bull Physiopathol Respir. 1973:9:452-6.

31. Bennett WD, Kala A, Zeman KL, Wu J, Henderson A, Albrecht H, et al. Effect of oral guaifenesin (Mucinex 1200mg) on mucociliary clearance from the lungs of healthy non-smoking adults. Poster 1178. 2010. vol. 
32. Bennett WD, Kala A, Duckworth H, Zeman KL, Wu J, Henderson A, et al. Effect of a single $1200 \mathrm{mg}$ dose of Mucinex(R) on mucociliary and cough clearance during an acute respiratory tract infection. Respir Med. 2015;109: 1476-83.

33. Sisson JH, Yonkers AJ, Waldman RH. Effects of guaifenesin on nasal mucociliary clearance and ciliary beat frequency in healthy volunteers. Chest. 1995;107:747-51.

34. Bolser DC. Cough suppressant and pharmacologic protussive therapy: ACCP evidence-based clinical practice guidelines. Chest. 2006;129:238S-49S.

35. Blanchard K, Ford RA. Effective antitussive agent in the treatment of cough in childhood. J Lancet. 1954;74:443-6.

36. Hayes EW, Jacobs LS. A clinical evaluation of the effectiveness of Robitussin in chronic cough. Chest. 1956;30:441-8.

37. Chodosh S. Glyceryl guaiacolate; a controlled laboratory and clinical study. (abstract). Am Rev Respir Dis. 1964;90:285-6.

38. Wojcicki J, Samochowiec L, Szwed G, Sawinski J. The use of Duopect as expectorant-antitussive agent. Arch Immunol Ther Exp. 1975;23:135-42.

39. Finiguerra M. Guaifenesin vs. Placebo in Chronic Bronchitis - Clinical Study Report. 1982. vol.

40. Hirsch SR, Viernes PF, Kory RC. The expectorant effect of glyceryl guaiacolate in patients with chronic bronchitis. A controlled in vitro and in vivo study. Chest. 1973;63:9-14.

41. Parvez L, Vaidya M, Sakhardande A, Subburaj S, Rajagopalan TG. Evaluation of antitussive agents in man. Pulm Pharmacol. 1996;9:299-308.

42. Robinson RE, Cummings WB, Deffenbaugh ER. Effectiveness of guaifenesin as an expectorant: a cooperative double-blind study Curr Ther Res. 1977;22:284-96.

43. Albrecht $H$, Vernon $M$, Solomon G. Patient-reported outcomes to assess the efficacy of extended-release guaifenesin for the treatment of acute respiratory tract infection symptoms. Respir Res. 2012;13:118.

44. Hoffer-Schaefer A, Rozycki HJ, Yopp MA, Rubin BK. Guaifenesin has no effect on sputum volume or sputum properties in adolescents and adults with acute respiratory tract infections. Respir Care. 2014;59:631-6.

45. Rosen EJ, Calhoun KH. Alterations of nasal mucociliary clearance in association with HIV infection and the effect of guaifenesin therapy. Laryngoscope. 2005;115:27-30.

46. Wawrose SF, Tami TA, Amoils CP. The role of guaifenesin in the treatment of sinonasal disease in patients infected with the human immunodeficiency virus (HIV). Laryngoscope. 1992;102:1225-8.

47. RMPDC. Rocky Mountain Poisons \& Drugs Center Surveillance Report, 1991-2008, data on file. 2008. vol.

48. RMPDC. Rocky Mountain Poisons \& Drugs Center Surveillance Report, 2008-2015, data on file. 2015. vol.

49. Assimos DG, Langenstroer $P$, Leinbach RF, Mandel NS, Stern JM, Holmes RP. Guaifenesin- and ephedrine-induced stones. J Endourol. 1999;13:665-7.

50. Wogoman H, Steinberg M, Jenkins AJ. Acute intoxication with guaifenesin, diphenhydramine, and chlorpheniramine. Am J Forensic Med Pathol. 1999;20:199-202.

51. Black RA, Hill DA. Over-the-counter medications in pregnancy. Am Fam Physician. 2003;67:2517-24.

52. Shabbir A, Shamsi S, Shahzad M, Butt HI, Aamir K, lqbal J. Evaluation of developmental toxicity of guaifenesin using pregnant female rats. Indian J Pharmacol. 2016;48(3):264-9.

53. Health Canada. Guidance document - nonprescription oral adult expectorant cough and cold labelling standard. 2014. http://www.hc-sc.gc ca/dhp-mps/prodpharma/applic-demande/guide-ld/label-etiquet-pharm/ cough-toux-eng.php. Accessed 1 Mar 2017.

54. Kuhn JJ, Hendley JO, Adams KF, Clark JW, Gwaltney JM Jr. Antitussive effect of guaifenesin in young adults with natural colds. Objective and subjective assessment. Chest. 1982;82:713-8.

\section{Submit your next manuscript to BioMed Central and we will help you at every step:}

- We accept pre-submission inquiries

- Our selector tool helps you to find the most relevant journal

- We provide round the clock customer support

- Convenient online submission

- Thorough peer review

- Inclusion in PubMed and all major indexing services

- Maximum visibility for your research

Submit your manuscript at www.biomedcentral.com/submit
Biomed Central 